report of a series of 16 cases of Hodgkin's disease involving Waldeyer's ring. ${ }^{1}$ In our series there was involvement of the nasopharynx in eight cases but, unlike the Swedish report, our cases were all ones in which biopsy of the nasopharynx was indicated by symptoms related to this area. In two of our patients the disease was primary in the nasopharynx; the other six had more widespread disease at the time of nasopharyngeal involvement. Seven of the eight cases were of the mixed cellularity type, the other showing a lymphocytic predominance type of change. None of our nasopharyngeal cases showed the epithelioid granuloma type of Hodgkin's change first described by Lennert and Mestdagh, ${ }^{2}$ in contrast to our seven tonsillar cases, four of which showed this change; this observation suggests that tonsillar Hodgkin's disease may of ten be a separate form of the disease. The cervical nodes that were involved in these cases also showed this epithelioid appearance.

Although in our series the course of the disease process did not seem to differ from that of the general pattern of Hodgkin's disease, it is possible that the presence or absence of microscopical Hodgkin's disease in the nasopharynx of a patient with disease elsewhere might be clinically important. The usefulness of this investigation could be ascertained only by carrying out a series of biopsies of the nasopharynx on an unselected group of patients with Hodgkin's disease at the time of primary diagnosis and comparing the findings with those in other tissues and with the fate of the patient. A detailed report of the findings of Dr Biörklund and his colleagues will therefore be awaited with interest.

Most cases of Hodgkin's disease present with enlarged lymph nodes. It is reasonable to postulate that the disease originates in Waldeyer's ring (an earlier station of the lymph node stream draining into the cervical lymph nodes) whether it spreads as a neoplasm or as a virus. The nasopharyngeal findings of $\mathrm{Dr}$ Biörklund and his colleagues and of ourselves are compatible with this concept and suggest that histological study of the nasopharynx in Hodgkin's disease will also further our fundamental knowledge of the disease process.

L MICHAELS

Department of Pathology and Bacteriology,

Institute of Laryngology and Otology,

Salisbury General Hospital,

GB TODD

1 Todd. G B, and Michaels, L, Cancer, 1974, 34, 2 Lennert, K, and Mestdagh, J, Virchows Archiv (Pathologische Anatomie), 1960, 344, 1 .

\section{Paraquat poisoning}

SIR,-Fortunately the incidence of accidental paraquat poisoning in the United Kingdom seems to have receded, but the number of cases of deliberate self-poisoning with this chemical persists at a worrying level. Many of the people concerned are apparently unaware of the ultimate consequence of thei acts.

An indication to prognosis can be derived from a relatively simple test on the urine. This test relies on the reduction of paraquat to a blue free radical by alkaline sodium dithionite. The reagent must be freshly pre- pared by adding $10 \mathrm{ml}$ of $1 \mathrm{M}$ sodium hydroxide $(1 \mathrm{~mol} / \mathrm{l})$ to $100 \mathrm{mg}$ of pure sodium dithionite. Aqueous paraquat standards are prepared containing $1.0,5.0$, and $10.0 \mathrm{mg} / \mathrm{l}(\mu \mathrm{g} / \mathrm{ml})$ of paraquat ion and 2 -ml aliquots of the sodium dithionite reagent are added to $10-\mathrm{ml}$ volumes of the test samples and paraquat standards. Quantitation is by visual inspection and the test is sensitive to $1.0 \mathrm{mg} / 1(\mu \mathrm{g} / \mathrm{ml})$ in clear urine. Since diquat is reduced to a green free radical, a green to blue colouration indicates Weedol ingestion.

If no colour change oocurs (that is, the result is negative) it can be assumed that no significant quantity of paraquat is being excreted and accordingly that no toxic amount has been absorbed. Active treatment can then be withheld. On the other hand a colour change to some shade of green or blue, while being no absolute criterion, certainly points towards an unfavourable outcome. These people, we think, should definitely be candidates for treatment. The first purpose of this letter, therefore, is to urge the provision in all emergency departments of facilities for this test throughout the 24 hours.

Regrettably at this stage no form of treatment can be confidently recommended, although several possibilities are being actively pursued at various centres throughout the country, the immediate treatment involving prompt but careful gastric aspiration and lavage, after which $500 \mathrm{ml}$ of a $30 \%$ suspension of fuller's earth $B P$ together with $5 \%$ magnesium sulphate is left in the stomach. The intention is to minimise absorption in the manner demonstrated in the successful findings of experiments in rats. ${ }^{1}$ Further details on this and the continuing treatment are available from this unit.

Animal experiments have also demonstrated that charcoal haemoperfusion produces both a good clearance of paraquat from the blood ${ }^{2}$ and survival. ${ }^{3}$ In this unit, as well as in several others, we are now studying the effectiveness of that technique in patients. For this purpose we need to receive patients with the least possible delay following ingestion and the second purpose of this letter is to invite clinicians who are confronted with cases of this kind to telephone us at once with a view to their transfer (01-407 7600, ext Poisons).

ROY GOULDING G N VolaNs PETER CROME B WIDDOP

National Poisons Information Service,

New Cross Hospital,

Poisons Unit,

1 Smith, L L, et al, British Medical fournal, 1974 4.569. L, et al, British Medical Fournal, 1974 Maini, 569 . Fournal, 1975, 3,261 .

Widdopal, $\mathbf{B}$, Procedings of Conference of the European Society for Artificial Organs, Berlin, 1975 , to be published.

Effect of smoking on carboxyhaemoglobin level in pregnancy

SIR,-Mr T G B Dow and his colleagues (1 November, $p$ 253) report that there is a significantly greater rise in blood carboxyhaemoglobin $(\mathrm{COHb})$ concentration in response to smoking a single cigarette in pregnant as opposed to non-pregnant women.
However, their study was confined to the second trimester of pregnancy and the subjects were instructed to puff every 40 seconds, inhaling as deeply as possible to a total of 10 puffs per cigarette.

I would like to point out that a different picture is obtained if subjects are allowed to smoke naturally. This approach was adopted in a longitudinal study of 10 pregnant smokers who were followed at 4-8-weekly intervals from 12-16 weeks of pregnancy to six weeks postnatally. The subjects were aged 19-30 years and had smoked 5-30 cigarettes daily for at least five years. At each attendance the subjects smoked one standard tipped cigarette (nicotine delivery $2.1 \mathrm{mg}$ ) in their "normal" manner. All tests were conducted at 9 am and the subjects had not smoked for $1 \frac{1}{2}$ hours before smoking the test cigarette. Details of subjects and procedure are described elsewhere. The number of puffs per cigarette decreased as pregnancy progressed from a mean of $14.66 \pm 0.76$ puffs per cigarette at 12-16 weeks (six subjects) to $11.4 \pm 0.93$ at $33-40$ weeks (10 subjects). Postnatally, the number of puffs per cigarette rose to $12.9 \pm 0.98$ (10 subjects). However, in the same subjects there was no significant change in the nicotine obtained from the cigarette at different stages of pregnancy.

In some of these subjects (not always the same subjects at each stage of pregnancy) estimations of blood $\mathrm{COHb}$ were obtained immediately before and immediately after smoking. Blood was taken from finger-prick samples (after preliminary experiments which showed that finger-prick and venous blood samples gave identical results) and $\mathrm{COHb}$ was estimated by the method of Commins and Lawther. ${ }^{2}$ The results from these few estimations showed that, like the puffing rate, the rise in $\mathrm{COHb}$ concentration after smoking decreased as pregnancy progressed, from $3 \cdot 17 \pm 0 \cdot 20 \%$ at $12-16$ weeks to $1 \cdot 09 \pm 0 \cdot 31 \%$ at $33-40$ weeks. Six weeks postnatally there was an increase to $1.80 \pm 0.34 \%$. The changes in $\mathrm{COHb}$ while smoking are shown in the figure, along with the puffing and nicotine data from the same subjects.

These observations indicate that women alter their smoking behaviour during pregnancy. Other observations have shown changes in smoking behaviour during stress and relaxation ${ }^{3}$ and with different strengths

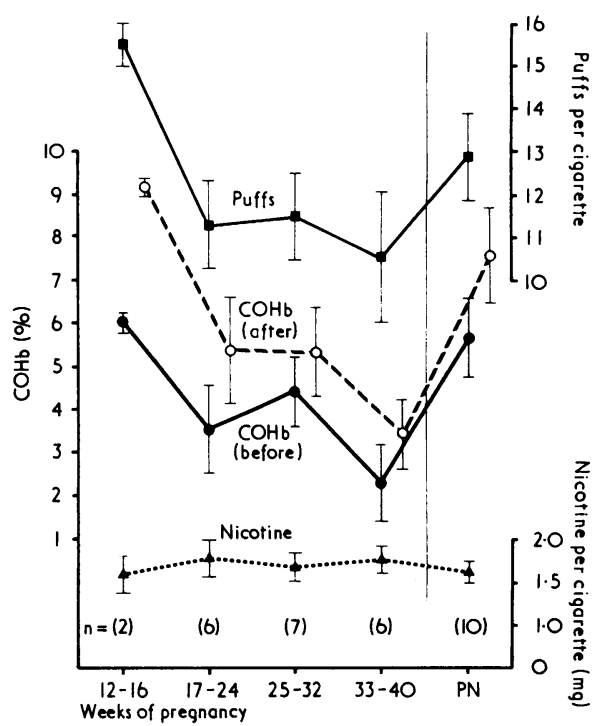


of cigarette ${ }^{35}$ and have also shown that smoking behaviour is influenced by personality characteristics. ${ }^{6}$ Alterations in smoking behaviour involve changes both in puffing rate and in depth of inhalation, each of which may modify the amount of nicotine, tar, and carbon monoxide absorbed. The present subjects decreased their puffing rate as pregnancy progressed but presumably inhaled more deeply, with the result that they managed to obtain the same amount of nicotine but apparently less carbon monoxide.

The cause of these changes is not clear, but the findings illustrate the dangers of extrapolation of data obtained during structured smoking regimens to real-life situations.

\section{HEATHER ASHTON}

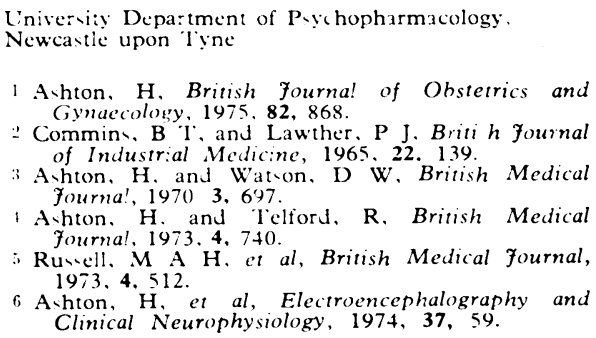

\section{Prevalence of thyroid disease in the elderly sick}

SIR,-Dr A W Burrows and his colleagues (22 November, p 437) appear to have got themselves into a complete muddle regarding the prevalence of thyroid disease in the elderly sick. They "disagree with reports that thyroid disease is prevalent (5\% or more of cases) in the elderly" as found by Jefferys': and Green" (note corrected reference). They cite Bahemuka and Hodkinson' and Thomson et al in support of their claim.

Their own study related to the investigation of a heterogenous group of 88 geriatric in- and out-patients, selected as being clinically euthyroid. None the less, they found two hypothyroid subjects, giving a thyroid prevalence of $2 \cdot 3$ ". with "exact" $95^{\circ} \%$ confidence limits of $0 \cdot 3-8.0 " \ldots$ In other words their result is compatible with a prevalence of $5 " .$, or more despite their exclusion of clinically apparent thyroid disease.

Their comparisons are biased ones as they did not compare like with like. Jefferys's 1 : prevalence of $5.7 "$ ", based on study of 317 unselected geriatric admissions to this department, referred to all thyroid disease, known, suspected, or unsuspected before investigation, and so did Green's" of "rather more than $7 " . "$ " based on a small inpatient series. The prevalence of $3.4 \%$ found in 2000 unselected admissions to this department by Bahemuka and Hodkinson' referred to suspected plus unsuspected cases. The work of Thomson et al: refers to well old people at home and is in no way comparable.

The only appropriate comparisons are with the findings of Jefferys and of Bahemuka and Hodkinson, with consideration only of the prevalence of unsuspected thyroid disease. These are shown in the table. Confidence limits are very wide for the smaller series so that useful conclusions cannot be drawn, but the large series of Bahemuka and Hodkinson indicates that the true prevalence of unsuspected thyroid disease is unlikely to be
Prevalence of unsuspocted thyroid disease in sick elderly patients

\begin{tabular}{|c|c|c|c|}
\hline Authors & $\begin{array}{c}\text { No of } \\
\text { cases total }\end{array}$ & $\begin{array}{c}\text { Preva:ence } \\
(\%)\end{array}$ & $\underset{\substack{\text { Confimits } \\
(\%)}}{\text { Conce }}$ \\
\hline $\begin{array}{l}\text { Burrows et al } \\
\text { Je.ferys : } \\
\text { Bahemuk and }\end{array}$ & $\begin{array}{l}2 / 88 \\
9 / 308\end{array}$ & $\begin{array}{l}2 \cdot 3 \\
3 \cdot 0\end{array}$ & $\begin{array}{l}0 \cdot 3-8 \cdot 0 \\
1 \cdot 4-5 \cdot 4\end{array}$ \\
\hline Hodkinsont & $44 / 1986$ & $2 \cdot 2$ & $1 \cdot 6-3 \cdot 0$ \\
\hline
\end{tabular}

as high as $5 \%$. There is no justification for saying that the total prevalence of thyroid disease in geriatric patients might not exceed this figure, however.

\section{H M HODKINSON}

\section{Northwick Park Hospital and Clinical} Research Centre

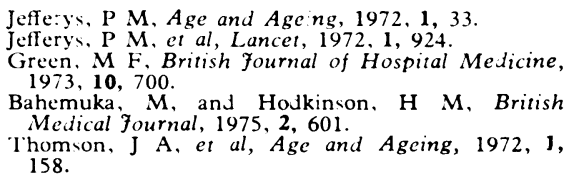

\section{Medical training in developing countries}

SIR,-May I comment on the observations of Dr Joyce E Leeson and Professor $R$ Illingworth (1 November, p 282) and $\mathrm{Dr}$ A J R Waterston (15 November, p 406) on our article on undergraduate medical education in a developing country (4 October, p 27)?

Dr Leeson and Dr Waterston feel that the British curriculum is a "historical relic" and "a probably outdated structure." Before we replace it with some new and untried alternative I think it worth remembering that this "historical relic" has trained some of the best doctors in the world. These are people who were able to function equally effectively in Harley Street as well as in the depths of Africa over the past century.

What seems remarkable is that many of our reformists seem to have forgotten that preventive and social medicine was taught (and is still taught) by good teachers of general medicine. I was a "victim" of this "outdated structure" but when I received instruction in pulmonary tuberculosis by an ordinary common or garden physician (also a product of the outdated structure) in $\mathrm{Dr}$ Leeson's own country a discussion on drug therapy was followed by a discussion on the preventive and social aspects of this disease. I am glad that Professor Illingworth has pointed this out. We decried the overemphasis of preventive and social medicine and the italics in our article were not accidental. It is interesting to note that this over-emphasis seems to be creeping into the new British curriculum. Professor Illingworth's fear that with some modern curricula new graduates will be unable to recognise an ill patient is, I am afraid, already a reality, and if a halt is not called the disease will spread.

Dr Leeson, having spent some five weeks in Cevlon, questions the validity of the figure of 973 hours spent in the teaching of preventive medicine in Colombo. This figure was quoted from one of the most extensive and exhaustive studies on medical education ever done in Ceylon. The members of the working group responsible for this report were the professors of psychiatry of Colombo and Peradeniva, the registrar of the university, the professor of obstetrics and the dean of medicine, Peradeniya, and the professor of physiology and the new head of the Postgraduate Institute, Colombo. These people, who were here when Dr Leeson visited this island, could have answered her queries.

Dr Leeson doubts our contention that tuberculosis presents the same problem in diagnosis and management everywhere. The disease was chosen after careful thought and we reaffirm that the management of this disease consists of recognition of the disease, therapy with effective drugs for a specified period, and the tracing of contacts and their management. These principles must be taught to medical students all over the world and this is what we meant when we said that there should be no difference in the basic training of doctors in developed and developing countries.

I do not disagree with Dr Waterston that poverty plays a major role in the causation of disease, but I fear the solution is more political than medical. To extend the example cited by him, consider an unemployed ex-tea-estate labourer suffering from protein malnutrition admitted to my ward. $\mathrm{He}$ is treated in hospital and returned to the street as Dr Waterston indicates. But why? It is not because my training has been such that I cannot appreciate the problem but because I am aware that until suitable employment is found and protein made available at a reasonable price there is no other alternative. $\mathrm{He}$ is returned to the street and not sent to a nutrition rehabilitation unit (leading article, 1 November, p 246). Even if they existed there would be only standing room since nearly half the population (and in Bangladesh almest the whole of the population) would be in them. That we in this fertile island, with water outside (by definition) and water inside (by the grace of God), are unable to provide an adequate supply of protein for our people is more a reflection of the way the country is run than on the way the doctors are trained. Changing the medical curriculum cannot provide either protein or employment.

University of Ceylon,

B SENEWIRATNE

Faculty of Medicine,

\section{British postgraduate qualifications in India}

SIR,-Better late than never. At last, the Indian Medical Council (IMC) has "derecognised" the so-called "high reputed" British postgraduate qualifications like the MRCP and FRCS. It was a move that had been pending for a long time, but no doubt hastened thanks to the GMC's recent decision about foreign doctors. It is a right and positive decision for the following reasons :

It is certainly going to dispel the illusion that exists in the minds of many Indian graduates about British postgraduate diplomas and thereby reduce the influx of overseas doctors into Britain. It will come as a great relief to those many immigrants who have wasted time, energy, and money over these postgraduate examinations-more so for those who doubt their impartiality. It will also, perhaps, stop the harassment of newcomers in having to undergo the General Medical Council's examination and the humiliation by the media of those overseas doctors who have already settled here. Many senior British doctors have the impression that the only reason immigrant doctors come to this country is to gain these postgraduate diplomas. This is far from being always the case and it should not therefore be such a prominent feature in interviews for medical posts. Many immigrant doctors come to Britain simply looking for better prospects in life-just like the British medical graduates who emigrate from this country.

\section{ᄋి}

